Supplement of Atmos. Chem. Phys., 18, 16121-16137, 2018

https://doi.org/10.5194/acp-18-16121-2018-supplement

(C) Author(s) 2018. This work is distributed under

the Creative Commons Attribution 4.0 License.

(c) (i)

Supplement of

\title{
Effects of meteorology and emissions on urban air quality: a quantitative statistical approach to long-term records (1999-2016) in Seoul, South Korea
}

Jihoon Seo et al.

Correspondence to: Jin Young Kim (jykim@kist.re.kr) and Daeok Youn (dyoun@chungbuk.ac.kr)

The copyright of individual parts of the supplement might differ from the CC BY 4.0 License. 
Supplement S1. Derivations of Eqs. (10) and (11).

By combining Eq. (9) and the time derivative of Eq. (8),

$\frac{\partial X_{\mathrm{LT}}}{\partial t}=\frac{\partial}{\partial t}\left(X_{\mathrm{LT}}^{\mathrm{emis}(\mathrm{T})}\right)+\frac{\partial}{\partial t}\left(X_{\mathrm{LT}}^{\mathrm{emis}(\mathrm{L})}+X_{\mathrm{LT}}^{\mathrm{met}}\right)=-\vec{V}_{\mathrm{LT}} \cdot \nabla X_{\mathrm{LT}}+S_{\mathrm{LT}}$

Since the advection term $\left(-\vec{V}_{\mathrm{LT}} \cdot \nabla X_{\mathrm{LT}}\right)$ represents the rate of changes in transport of regional emissions $\left(\frac{\partial}{\partial t}\left(X_{\mathrm{LT}}^{\text {emis }(\mathrm{T})}\right)\right)$,

$\frac{\partial}{\partial t}\left(X_{\mathrm{LT}}^{\mathrm{emis}(\mathrm{T})}\right)=-\vec{V}_{\mathrm{LT}} \cdot \nabla X_{\mathrm{LT}}=-\left(u_{\mathrm{LT}} \frac{\partial X_{\mathrm{LT}}}{\partial x}+v_{\mathrm{LT}} \frac{\partial X_{\mathrm{LT}}}{\partial y}\right)$

$\frac{\partial}{\partial t}\left(X_{\mathrm{LT}}^{\mathrm{emis}(\mathrm{L})}+X_{\mathrm{LT}}^{\mathrm{met}}\right)=S_{\mathrm{LT}}$

By substitution of Eq. (4) $\left(X_{\mathrm{LT}}=X_{\mathrm{BL}}-X_{\mathrm{SN}}\right)$ into Eq. (S2), Eq. (10) can be derived as follows:

$\frac{\partial}{\partial t}\left(X_{\mathrm{LT}}^{\mathrm{emis}(\mathrm{T})}\right)=-u_{\mathrm{LT}} \frac{\partial X_{\mathrm{LT}}}{\partial x}-v_{\mathrm{LT}} \frac{\partial X_{\mathrm{LT}}}{\partial y}=-u_{\mathrm{LT}} \frac{\partial}{\partial x}\left(X_{\mathrm{BL}}-X_{\mathrm{SN}}\right)-v_{\mathrm{LT}} \frac{\partial}{\partial y}\left(X_{\mathrm{BL}}-X_{\mathrm{SN}}\right)$

Also, from Eq. (S1), $\frac{\partial}{\partial t}\left(X_{\mathrm{LT}}^{\mathrm{emis}(\mathrm{L})}\right)$ can be expressed as Eq. (11) as follows:

$\frac{\partial}{\partial t}\left(X_{\mathrm{LT}}^{\mathrm{emis}(\mathrm{L})}\right)=\frac{\partial X_{\mathrm{LT}}}{\partial t}-\frac{\partial}{\partial t}\left(X_{\mathrm{LT}}^{\mathrm{emis}(\mathrm{T})}\right)-\frac{\partial}{\partial t}\left(X_{\mathrm{LT}}^{\mathrm{met}}\right)$ 
Table S1. Degrees of freedom (dof) of each time series of short-term, baseline, and long-term components calculated based on Leith (1973).

\begin{tabular}{llllllllllll}
\hline dof & $\mathrm{PM}_{10}$ & $\mathrm{SO}_{2}$ & $\mathrm{NO}_{2}$ & $\mathrm{CO}$ & $\mathrm{O}_{38 \mathrm{~h}}$ & $\mathrm{~T}$ & $\mathrm{~T}_{\max }$ & $\mathrm{P}$ & $\mathrm{RH}$ & $\mathrm{WS}$ & $\mathrm{SI}$ \\
\hline$X_{\mathrm{ST}}$ & 1054 & 1084 & 1084 & 1084 & 1626 & 1084 & 1084 & 1084 & 1084 & 1626 & 1622 \\
$X_{\mathrm{BL}}$ & 45 & 45 & 55 & 35 & 50 & 46 & 47 & 47 & 60 & 36 & 58 \\
$X_{\mathrm{LT}}$ & 2 & 5 & 2 & 4 & 2 & 7 & 7 & 9 & 7 & 2 & 8 \\
$X_{\mathrm{LT}}^{\text {emis }}$ & 2 & 6 & 4 & 8 & 2 & & & & & & \\
$X_{\mathrm{LT}}^{\text {met }}$ & 3 & 6 & 3 & 2 & 2 & & & & & & \\
\hline
\end{tabular}

Leith, C. E.: The standard error of time-average estimates of climatic means, J. Appl. Meteor., 12, 1066-1069, https://doi.org/10.1175/1520-0450(1973)012<1066:TSEOTA>2.0.CO;2, 1973.

Table S2. Coefficients of determination $\left(R^{2}\right)$ between each component and original time series $(X)$ for Seoul average concentrations of $\mathrm{PM}_{10}, \mathrm{SO}_{2}, \mathrm{NO}_{2}, \mathrm{CO}$, and $\mathrm{O}_{3}$ sh. Daily data for the period of July 2000 to Jun 2015 that $X_{\mathrm{LT}}$ data is available were used.

\begin{tabular}{cllllll}
\hline Components & $\mathrm{PM}_{10}$ & $\mathrm{SO}_{2}$ & $\mathrm{NO}_{2}$ & $\mathrm{CO}$ & $\mathrm{O}_{38 \mathrm{~h}}$ & Notes \\
\hline$X_{\mathrm{ST}}$ & 0.699 & 0.541 & 0.724 & 0.503 & 0.474 & Short-term components \\
\hline$X_{\mathrm{SN}}$ & 0.276 & 0.468 & 0.287 & 0.397 & 0.522 & Seasonal components \\
\hline$X_{\mathrm{LT}}$ & 0.081 & 0.055 & 0.038 & 0.152 & 0.057 & Long-term components \\
$X_{\mathrm{LT}}^{\text {emis }}$ & 0.064 & 0.054 & 0.030 & 0.124 & 0.043 & Emission-related $X_{\mathrm{LT}}$ \\
$X_{\mathrm{LT}}^{\text {met }}$ & 0.069 & 0.003 & 0.019 & 0.107 & 0.040 & Meteorology-related $X_{\mathrm{LT}}$ \\
\hline
\end{tabular}


(a) Available monitoring sites in Seoul $\left(\mathrm{PM}_{10}\right)$

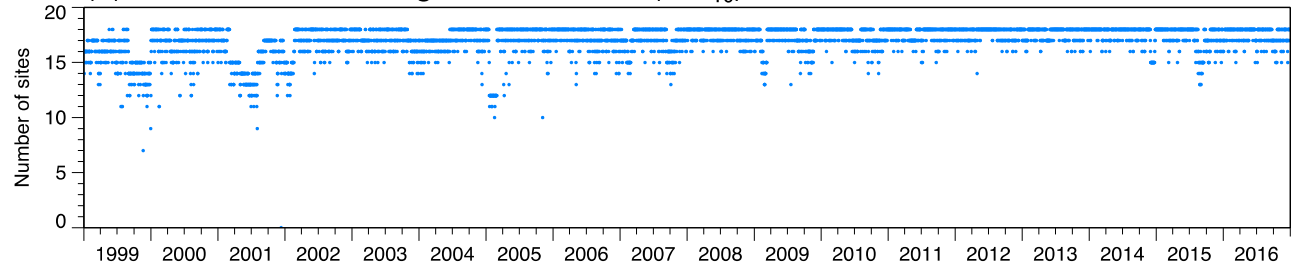

(b) Average $\mathrm{PM}_{10}$ concentration (Seoul)

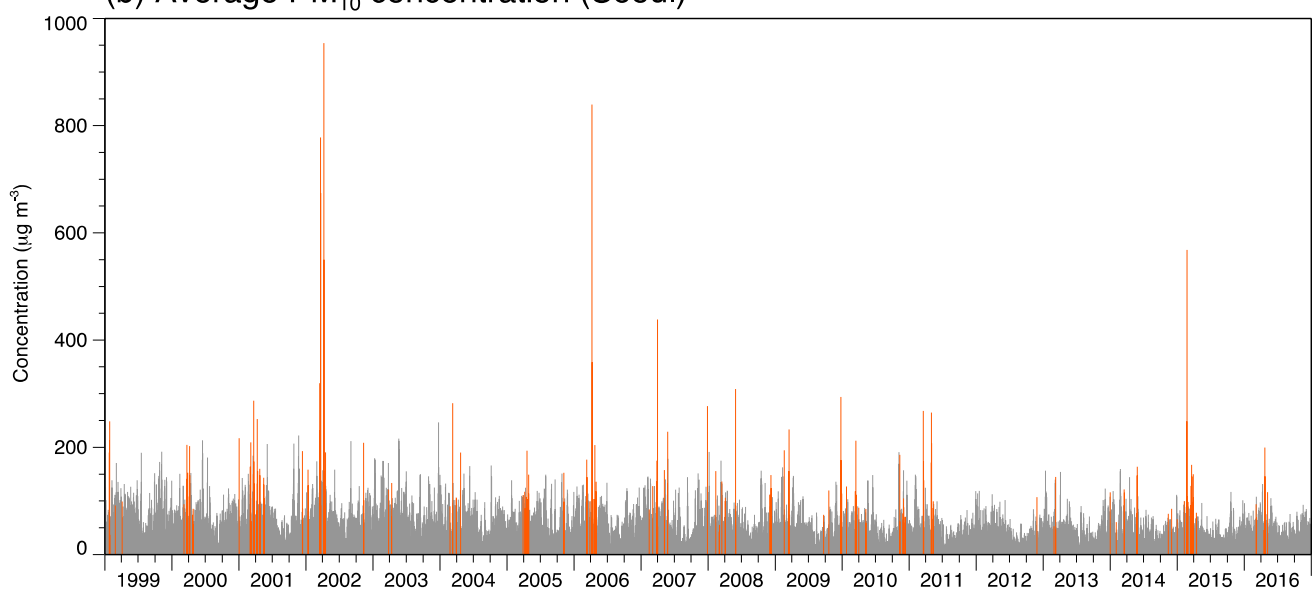

(c) Standard deviation of $\mathrm{PM}_{10}$ concentration (Seoul)

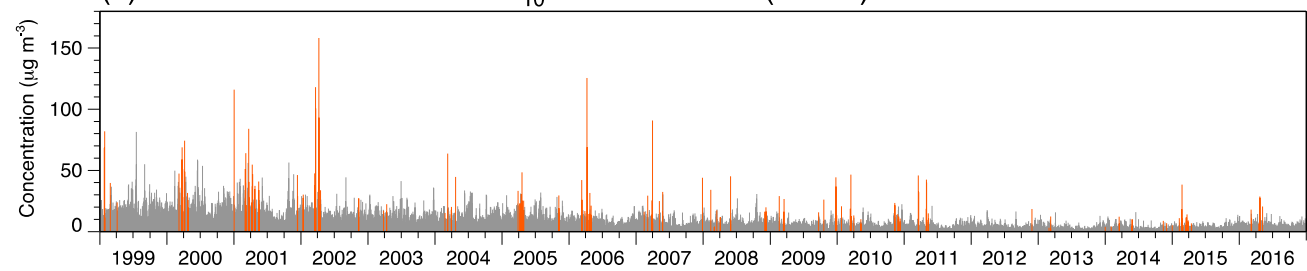

Figure S1. (a) Numbers of available air quality monitoring sites in Seoul, of which missing data are less than $10 \%$ of the total. (b) Average and (c) standard deviation of $P M_{10}$ concentrations of the available 18 sites in Seoul. Asian dust events those were excluded from the PM10 analysis are marked with orange color. 
(a) $\mathrm{PM}_{10}$

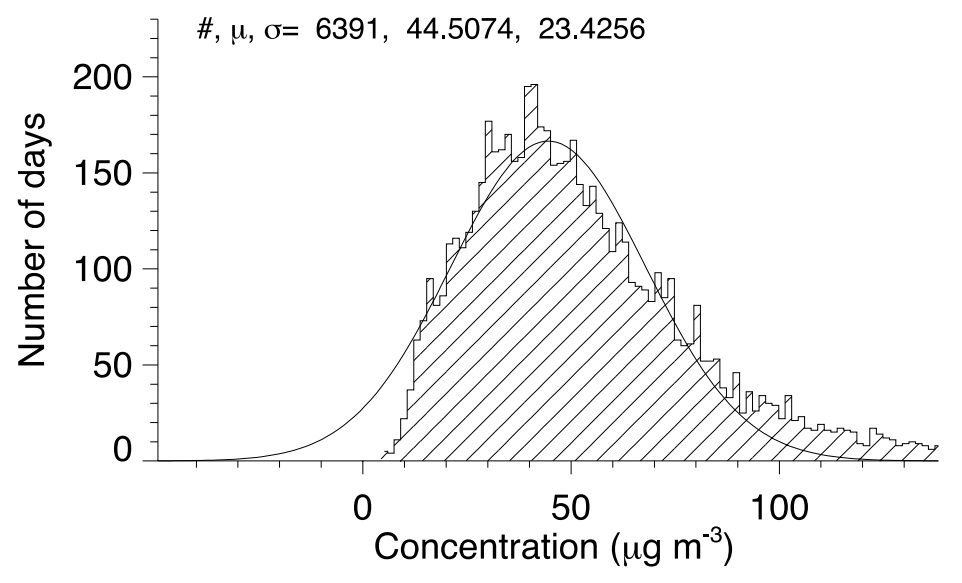

(b) $\ln \left(\mathrm{PM}_{10}\right)$

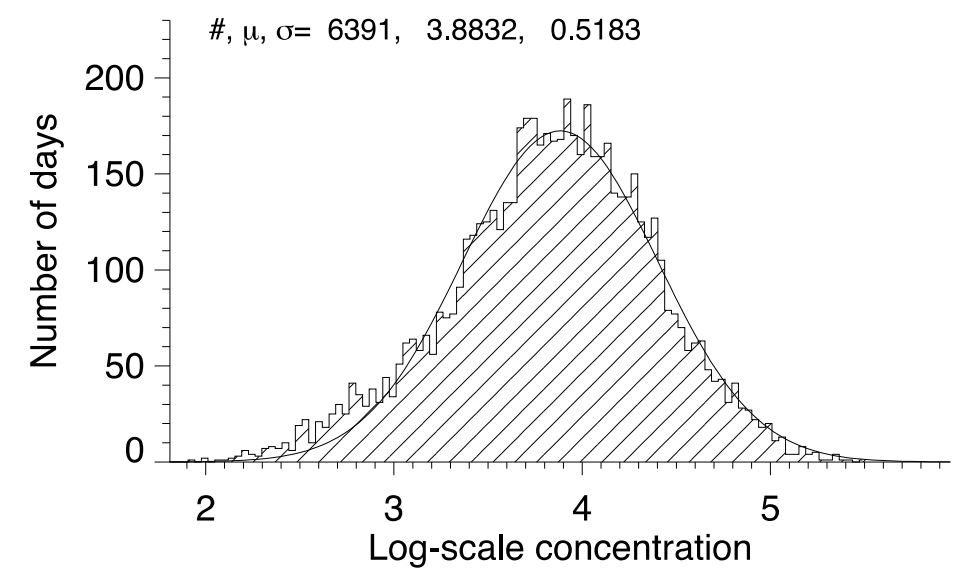

Figure S2. Number distribution of (a) daily average $P_{10}$ concentration and (b) log-transformed daily average $P M_{10}$ concentration. The bell shaped curves show normal (Gaussian) distributions, and \#, $\mu$, and $\sigma$ denote the total number of days, mean values, and standard deviation, respectively. Asian dust event days were excluded from the analysis. 
(a) $\mathrm{PM}_{10}$

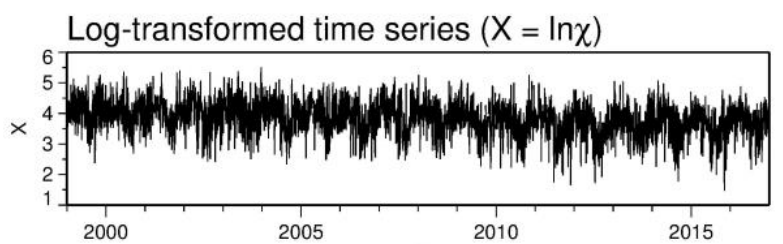

Short-term component $\left(\mathrm{X}_{\mathrm{ST}}\right)$

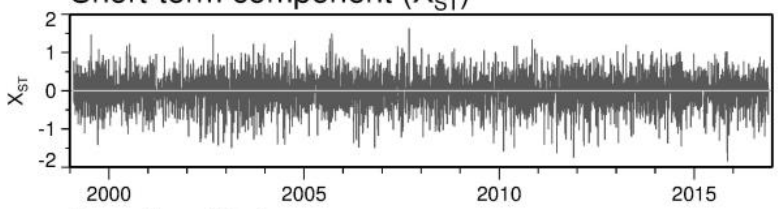

Baseline $\left(X_{B L}\right)$

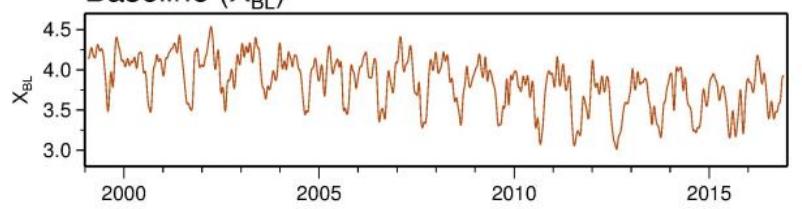

Seasonal component $\left(\mathrm{X}_{\mathrm{SN}}\right)$

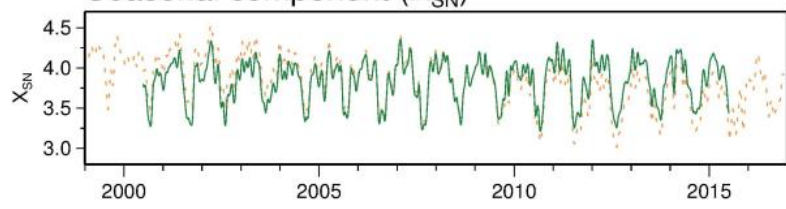

Long-term component $\left(\mathrm{X}_{\mathrm{LT}}\right)$

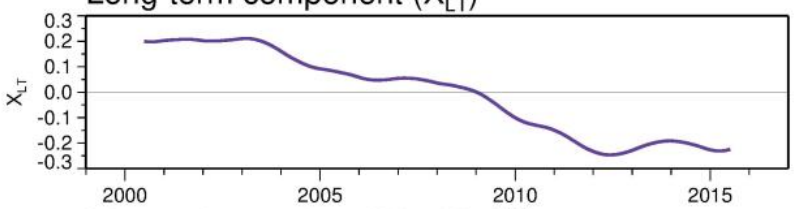

Meteorology-related $X_{L T}\left(X_{L T}{ }^{\text {met }}\right)$

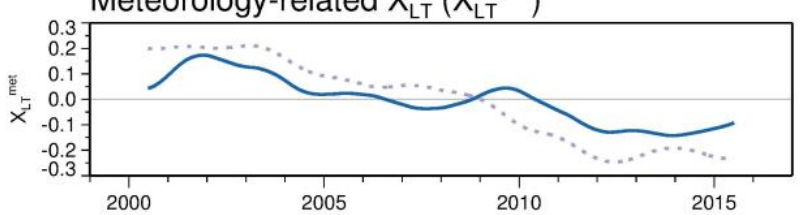

Emission-related $\mathrm{X}_{\mathrm{LT}}\left(\mathrm{X}_{\mathrm{LT}}{ }^{\mathrm{emis}}\right)$

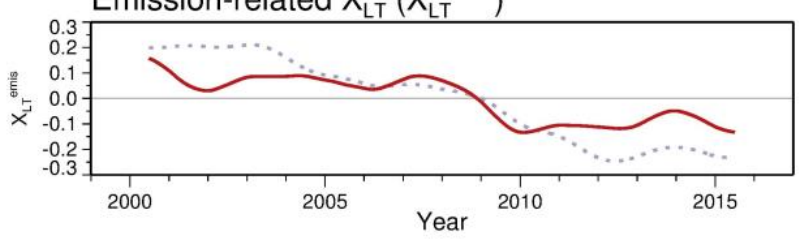

Figure S3. Decompositions of log-scale daily time series of (a) $\mathrm{PM}_{10}$ and (b) $\mathrm{O}_{3}$ sh those averaged for 18 sites in Seoul. (b) $\mathrm{O}_{38 \mathrm{~h}}$
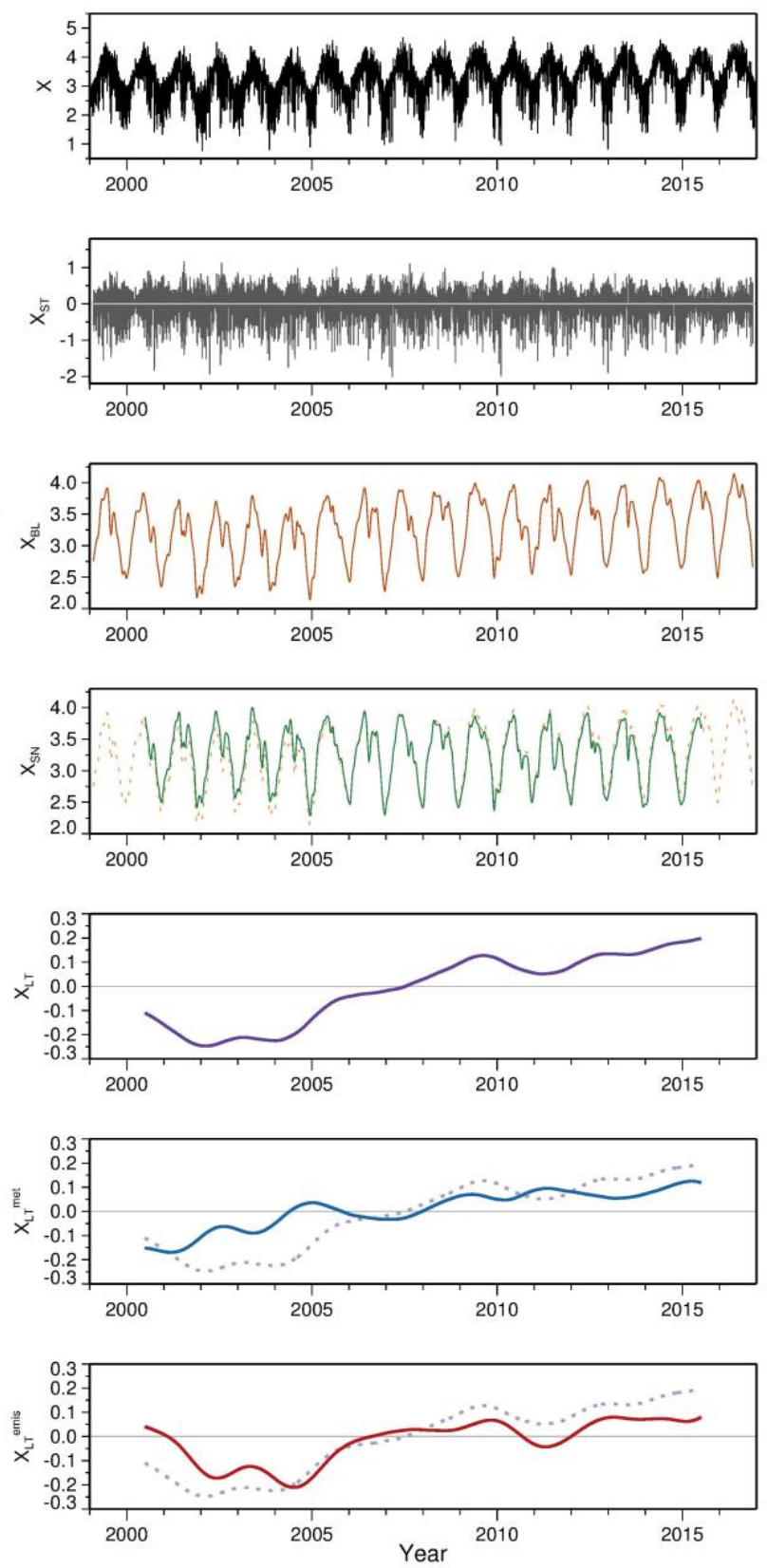
(a) X (log-scale $\mathrm{PM}_{10}$ )

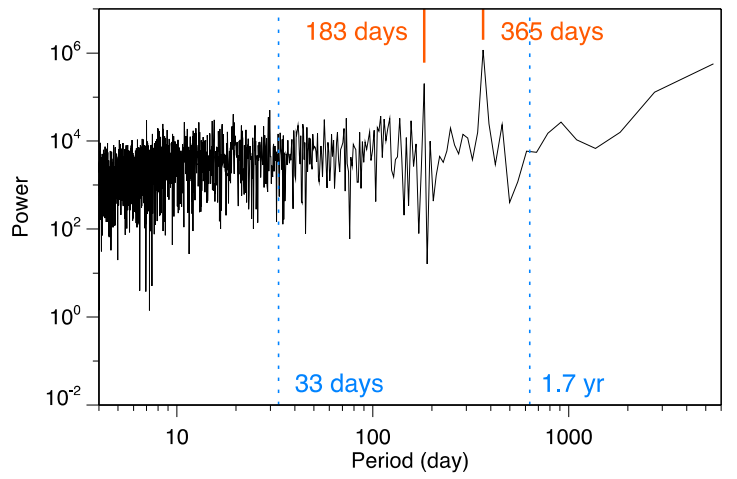

(c) $X_{S N}$ (Seasonal component)

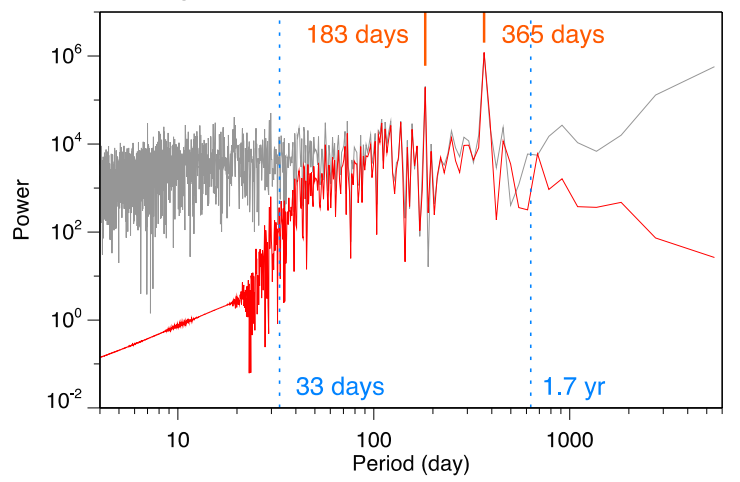

(b) $\mathrm{X}_{\mathrm{ST}}$ (Short-term component)

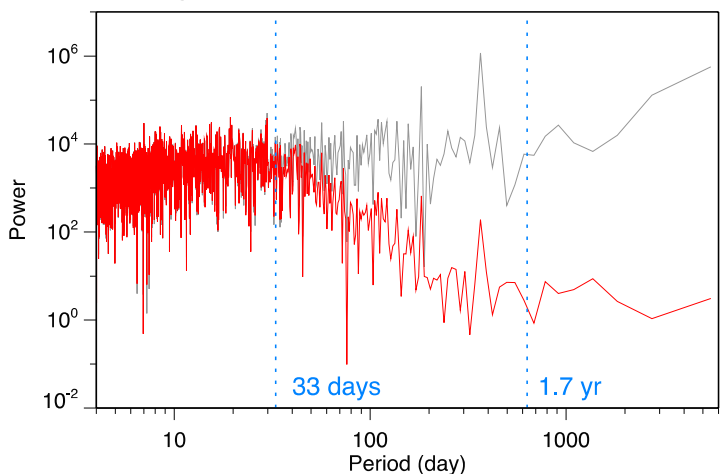

(d) $X_{L T}$ (Long-term component)

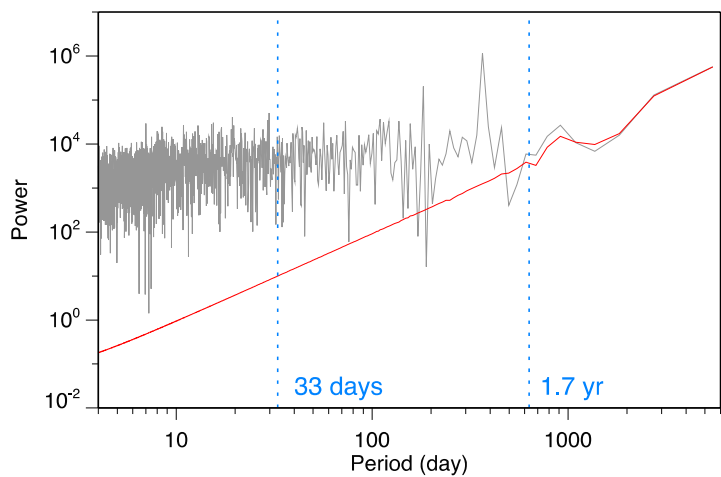

Figure S4. Power spectra of (a) log-transformed daily average $P M_{10}$ concentration time series (a black line) and its (b) short-term, (c) seasonal, and (d) long-term components (red lines). Effective filter widths for $\mathrm{KZ}_{(\mathbf{1 5 , 5})}$ filter $(33$ days) and $\mathrm{KZ}_{(365,3)}$ filter (632 days) are marked with blue vertical dashed lines. The power spectrum of the original time series in (a) is represented with gray lines in (b-d). 

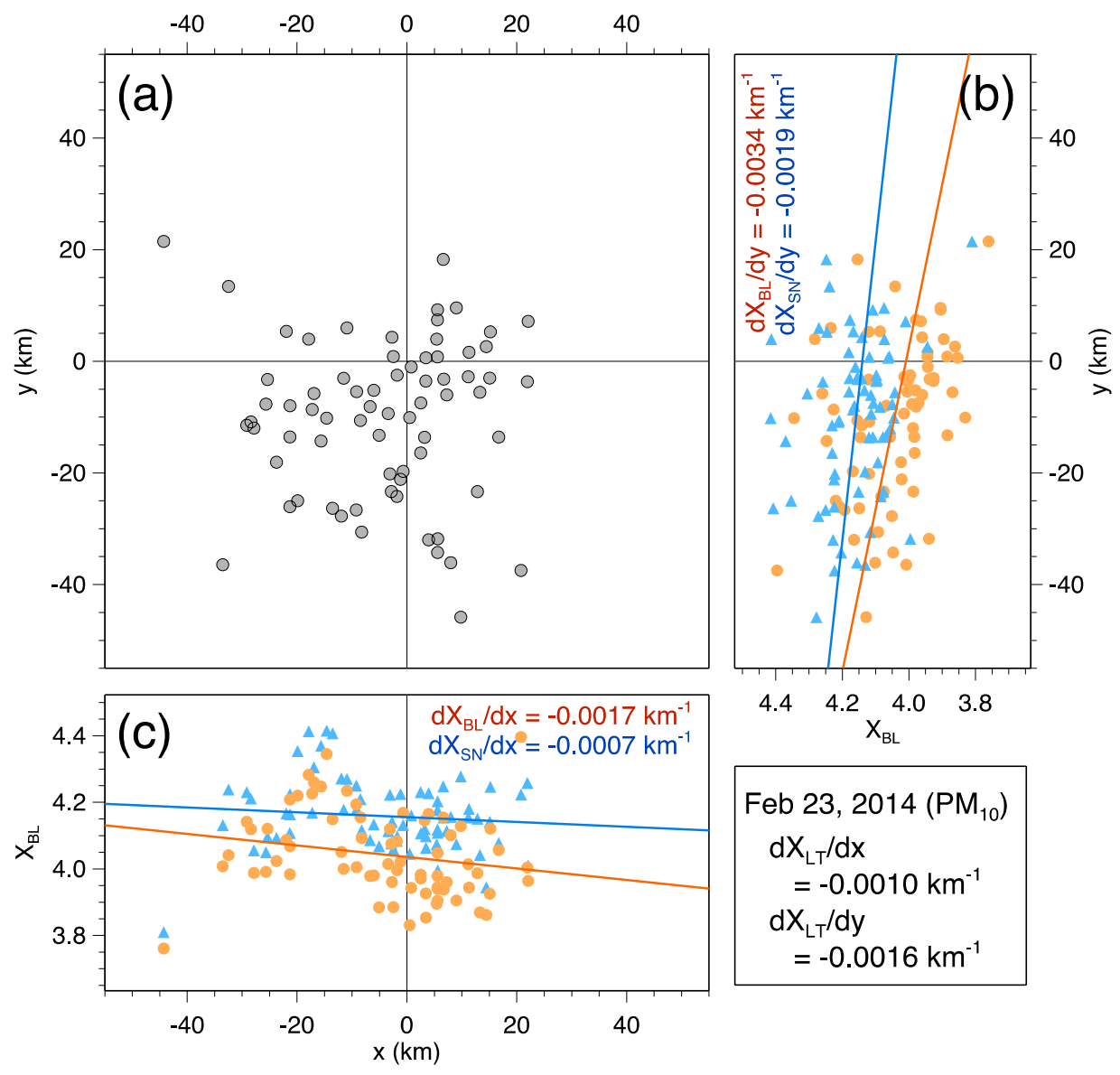

Feb 23, $2014\left(\mathrm{PM}_{10}\right)$

$\mathrm{dX} \mathrm{K}_{\mathrm{LT}} / \mathrm{dx}$

$=-0.0010 \mathrm{~km}^{-1}$

$\mathrm{dX} \mathrm{X}_{\mathrm{LT}} / \mathrm{dy}$

$=-0.0016 \mathrm{~km}^{-1}$

Figure S5. An example of obtaining horizontal gradient of long-term component $\left(X_{\mathrm{LT}}\right)$ of PM10 on 23 February 2014 . (a) Locations of 70 air quality monitoring sites in Cartesian coordinates centered at the Seoul weather station $\left(37.57^{\circ} \mathrm{N}\right.$, $126.97^{\circ} \mathrm{E}$ ), of which data availability were more than $75 \%$ for the period of $1999-2016$. (b) Meridional gradients of the baseline $\left(\frac{\partial X_{\mathrm{BL}}}{\partial y}\right)$ and seasonal component $\left(\frac{\partial X_{\mathrm{SN}}}{\partial y}\right)$ obtained by linear regressions. (c) Zonal gradients of the baseline $\left(\frac{\partial X_{\mathrm{BL}}}{\partial x}\right)$ and seasonal component $\left(\frac{\partial X_{S N}}{\partial x}\right)$. Zonal and meridional gradient of the long-term component can be gained by subtracting the seasonal component gradients from the baseline gradients $\left(\frac{\partial X_{\mathrm{LT}}}{\partial x}=\frac{\partial X_{\mathrm{BL}}}{\partial x}-\frac{\partial X_{\mathrm{SN}}}{\partial x}, \frac{\partial X_{\mathrm{LT}}}{\partial y}=\frac{\partial X_{\mathrm{BL}}}{\partial y}-\frac{\partial X_{\mathrm{SN}}}{\partial y}\right)$. 
(a) $u_{L T}($ Seoul $)$

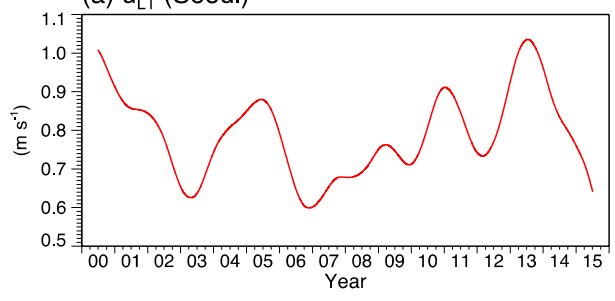

(c) $\mathrm{PM}_{10 \mathrm{LT}}$ horizontal gradient

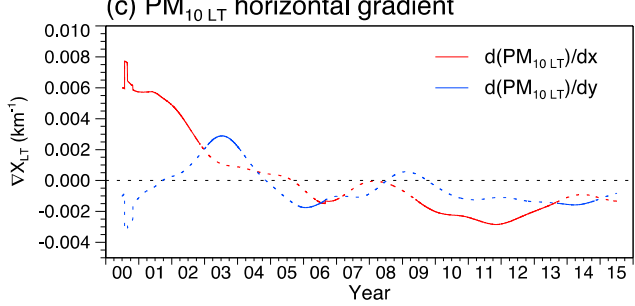

(e) $\mathrm{CO}_{\mathrm{LT}}$ horizontal gradient

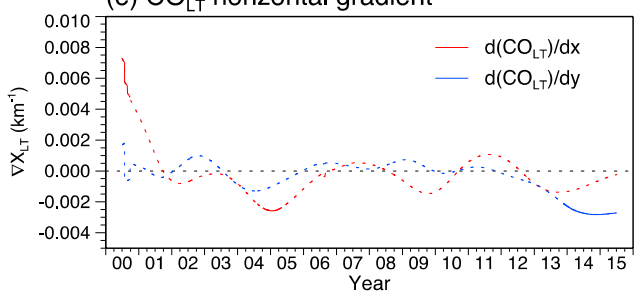

(g) $\mathrm{SO}_{2 \mathrm{LT}}$ horizontal gradient

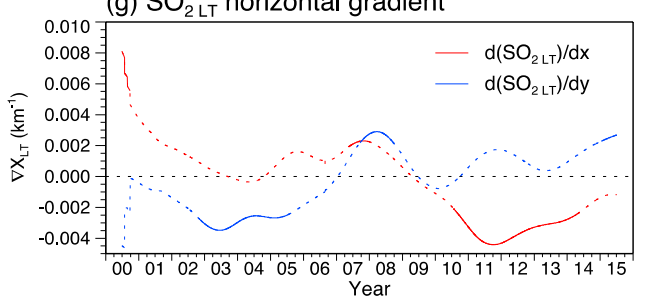

(i) $\mathrm{NO}_{2 L T}$ horizontal gradient

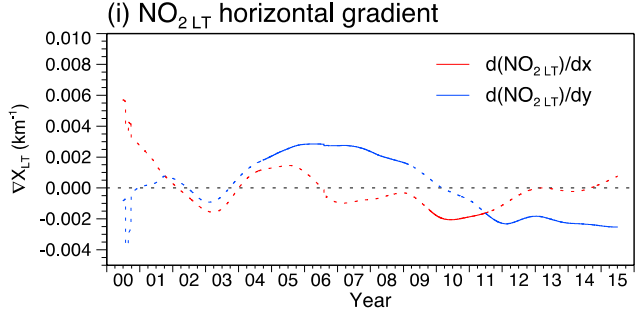

(k) $\mathrm{O}_{38 \mathrm{hLT}}$ horizontal gradient

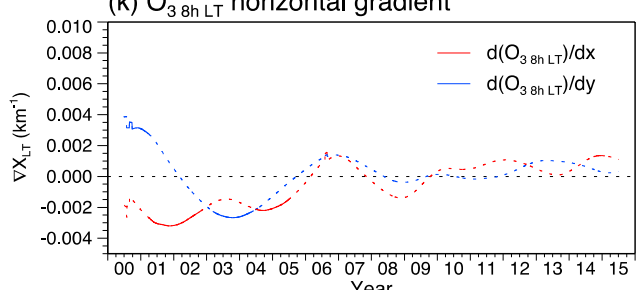

(b) $\mathrm{v}_{\mathrm{LT}}($ Seoul)

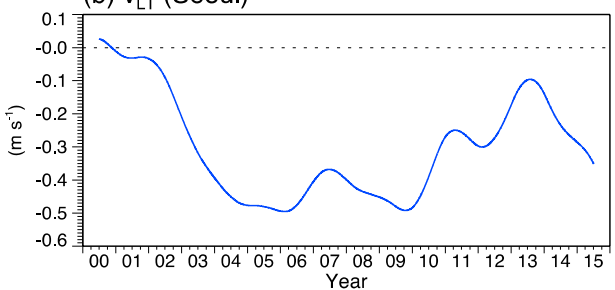

(d) $\mathrm{PM}_{10 \mathrm{LT}}$ transport term $\left(\mathrm{dPM}_{10 \mathrm{LT}}{ }^{\mathrm{emis}(\mathrm{T})} / \mathrm{dt}\right)$
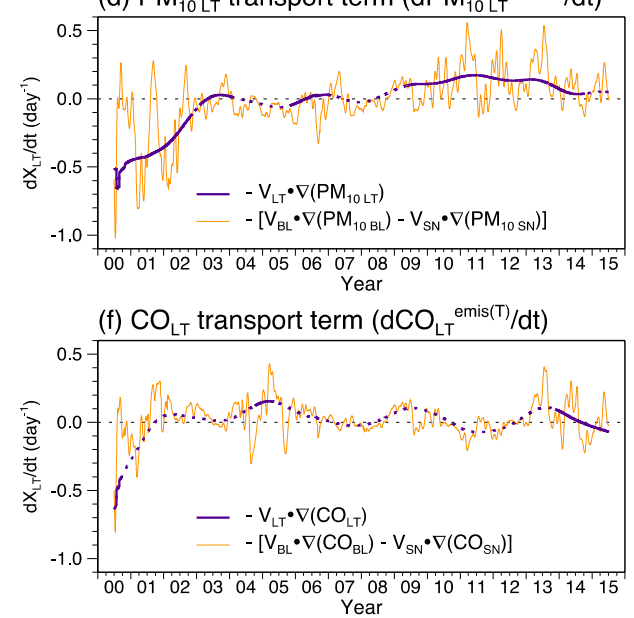

(h) $\mathrm{SO}_{2 \mathrm{LT}}$ transport term $\left(\mathrm{dSO}_{2 \mathrm{LT}}{ }^{\mathrm{emis}(\mathrm{T})} / \mathrm{dt}\right)$
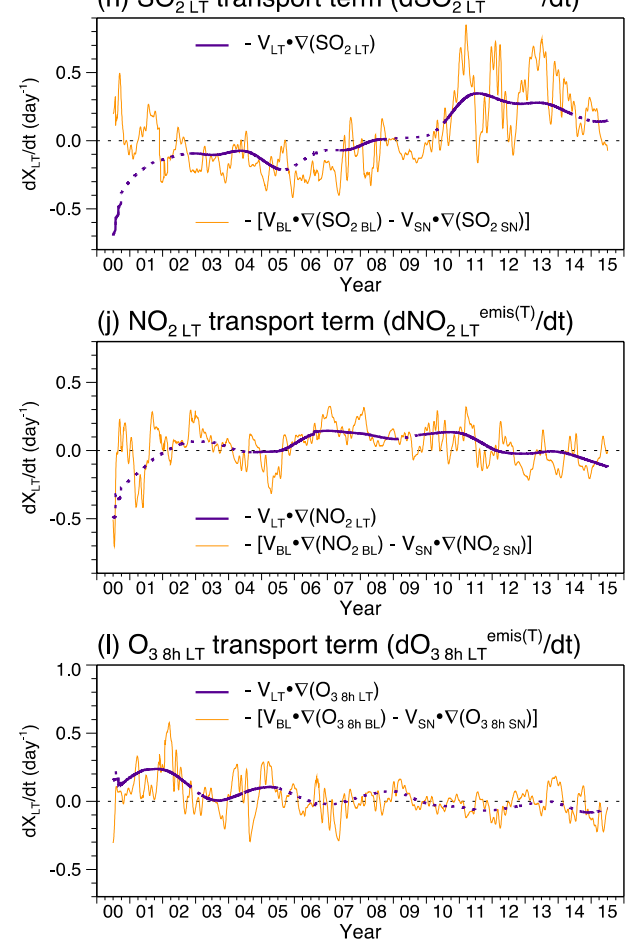

Figure S6. Long-term component of (a) zonal wind $\left(u_{\mathrm{LT}}\right)$ and $(\mathrm{b})$ meridional wind $\left(v_{\mathrm{LT}}\right)$ at the Seoul weather station. Zonal gradients $\left(\partial X_{\mathrm{LT}} / \partial x\right.$, red lines) and meridional gradients $\left(\partial X_{\mathrm{LT}} / \partial y\right.$, blue lines $)$ of the long-term components and transport terms $\left(-\vec{V}_{\mathrm{LT}} \cdot \nabla X_{\mathrm{LT}}\right.$, violet lines) by long-term components of horizontal winds $\left(\vec{V}_{\mathrm{LT}}=\left(\boldsymbol{u}_{\mathrm{LT}}, v_{\mathrm{LT}}\right)\right)$ for $(\mathrm{c}-\mathrm{d})$ $\mathrm{PM}_{10}$, (e-f) $\mathrm{CO},(\mathrm{g}-\mathrm{h}) \mathrm{SO}_{2},(\mathrm{i}-\mathrm{j}) \mathrm{NO}_{2},(\mathrm{k}-\mathrm{l}) \mathrm{O}_{3} \mathrm{sh}$. Solid lines in horizontal gradients and transport terms indicate that the gradients obtained by linear regression are statistically significant at the $95 \%$ level or higher $(p<0.05)$. 

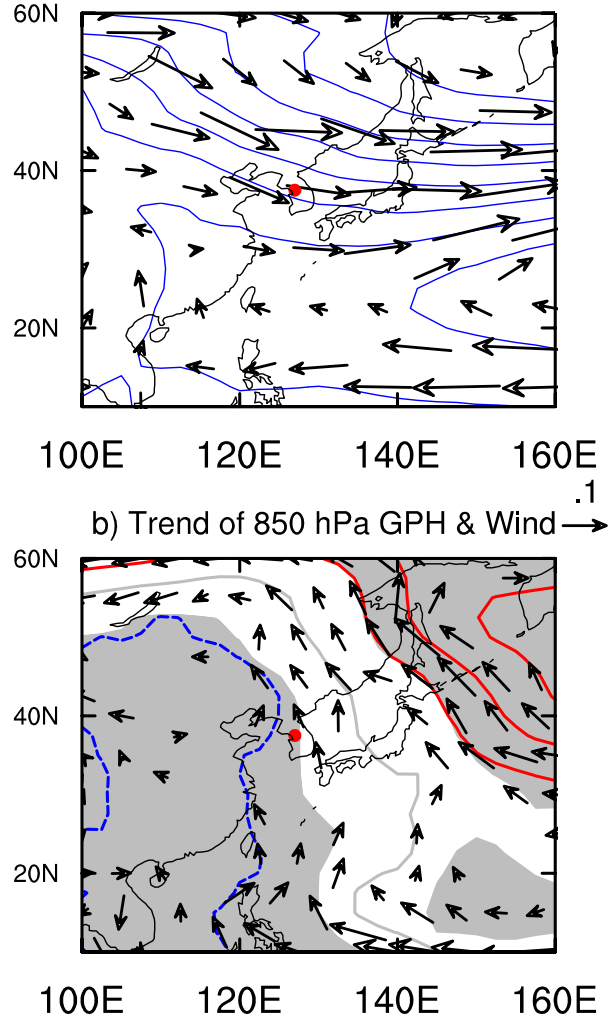

c) Trend of $10 \mathrm{~m}$ wind

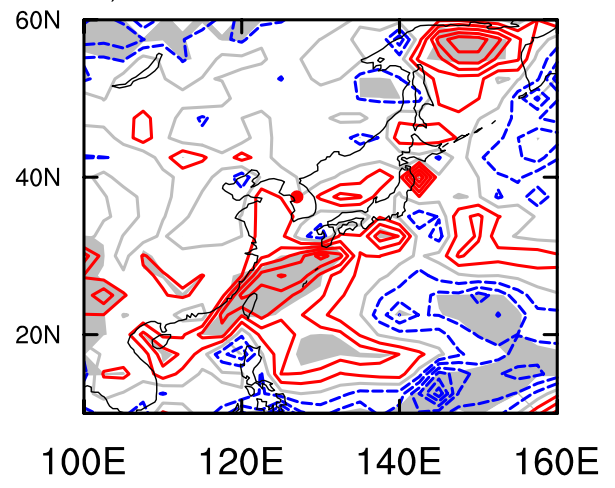

Figure S7. (a) Mean geopotential height (contours with interval of $20 \mathrm{gpm}$ ) and wind fields (arrows with reference scale of $3 \mathrm{~m} \mathrm{~s}^{-1}$ ) at $850 \mathrm{hPa}$, and linear trends of (b) geopotential height (contours with interval of $0.5 \mathrm{gpm} \mathrm{yr}^{-1}$ ) and wind (arrows with reference scale of $0.1 \mathrm{~m} \mathrm{~s}^{-1} \mathrm{yr}^{-1}$ ) at $850 \mathrm{hPa}$ and (c) $10 \mathrm{~m}$ wind speed (contours with interval of $0.01 \mathrm{~m} \mathrm{~s}^{-1} \mathrm{yr}^{-1}$ ) for the period of 2000-2015. The trends statistically significant at $95 \%$ confidence level in (b) and (c) are represented as gray shaded areas and wind arrows. Seoul is marked by solid red circles. 
(a)

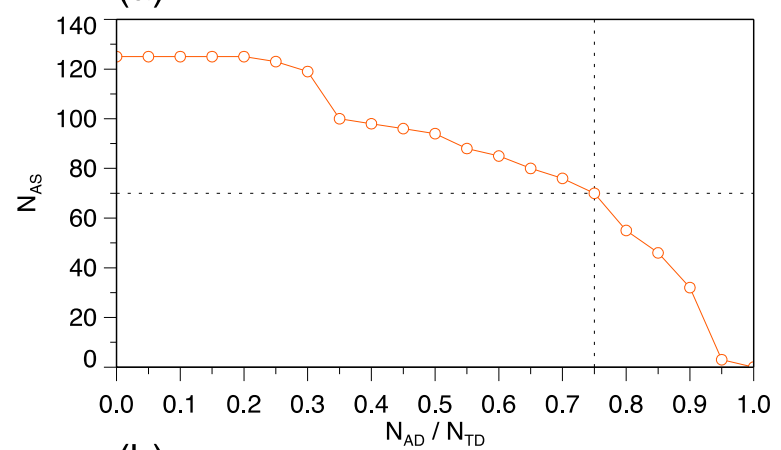

(b)

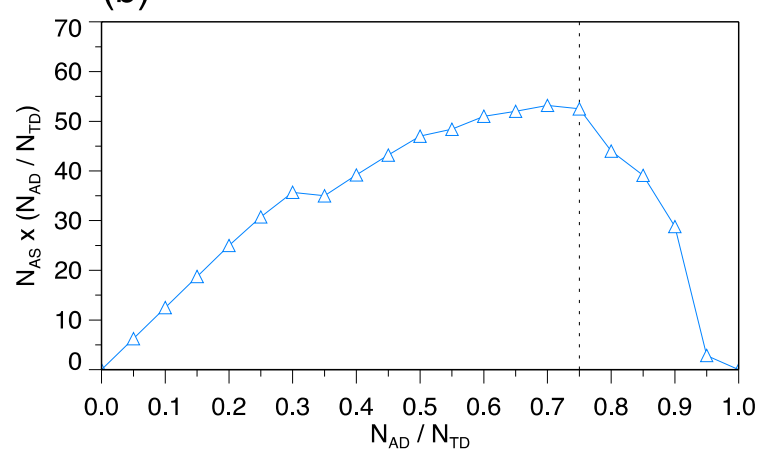

Figure S8. (a) Numbers of available air quality monitoring sites $\left(\mathrm{N}_{\mathrm{AS}}\right)$ within the area of $50 \mathrm{~km}$ radius from the Seoul weather station and (b) $N_{A S}$ multiplied with ratios of the available number of data $\left(N_{A D}\right)$ to the total number of data $\left(N_{T D}\right)$. Vertical dotted lines at $\mathrm{N}_{\mathrm{AD}} / \mathrm{N}_{\mathrm{TD}}$ of 0.75 show the data availability of $75 \%$ and a horizontal dotted line at $\mathrm{N}_{\mathrm{AS}}$ of 70 represents the number of air quality monitoring sites used for obtaining the horizontal gradient of long-term components in this study. 